\title{
Endothelium Dependency of Contractile Activity Differs in Infant and Adult Vertebral Arteries
}

John R. Charpie, Kevin D. Schreur, Stephen M. Papadopoulos, and R. Clinton Webb

Departments of Pediatric Cardiology, Surgery, and Physiology, The University of Michigan Medical School, Ann Arbor, Michigan 48109-0622

\begin{abstract}
Contractions to serotonin (5-HT) and endothelin-1 (ET-1) in infant (0-2 yr) and adult (38-71 yr) vertebral arteries were examined in the presence of either the cyclooxygenase inhibitor indomethacin or $\boldsymbol{N}^{\mathrm{G}}$-monomethyl-L-arginine (L-NMMA), an inhibitor of nitric oxide production. In addition, endotheliumdependent relaxations to acetylcholine were characterized in arteries contracted with agonist. The results showed that: $(a)$ Contractions of infant arteries to 5-HT or ET-1 decreased to $44 \pm 8 \%$ and $27 \pm 13 \%$, respectively, within $10 \mathrm{~min}$. Indomethacin or removal of endothelium abolished this decreased response, whereas L-NMMA had no effect. (b) Adult arteries produced sustained contractions to 5-HT or ET-1 that were unaffected by indomethacin, endothelium denudation, or LNMMA. (c) Endothelium-dependent relaxations to acetylcholine were greater in infant than adult arteries and were abolished by indomethacin (but not L-NMMA) in infants and L-NMMA (but not indomethacin) in adults. Thus, endothelium-dependent responses in infant arteries are attenuated because of increased prostaglandin activity not observed in adult tissues.

Additionally, there is an age-dependent change in the primary mechanism responsible for acetylcholine-induced vasodilatation. Apparently, endothelium dependency of acetylcholine-induced relaxation is highly dependent on cyclooxygenase activity in the infant vertebral artery, but in the adult artery, nitric oxide is linked to the vasodilator response. (J. Clin. Invest. 1994. 93:1339-1343.) Key words: nitric oxide • serotonin • endothelin-1 $\bullet$ acetylcholine $\bullet$ prostaglandins
\end{abstract}

\section{Introduction}

Numerous investigators have documented the effects of normal development and aging on the vascular endothelium. Morphometric analysis suggests that aging is associated with thinning and loss of endothelium $(1,2)$ and functional evidence supports an age-related impairment in endothelium-depen-

Address correspondence to Dr. John R. Charpie, Department of Physiology, University of Michigan Medical School, 7813 Medical Sciences Building II, Ann Arbor, MI 48109-0622.

Received for publication 7 June 1993 and in revised form 2 November 1993.

J. Clin. Invest.

(c) The American Society for Clinical Investigation, Inc.

$0021-9738 / 94 / 03 / 1339 / 05 \$ 2.00$

Volume 93, March 1994, 1339-1343 dent relaxation in thoracic aortae (3), mesenteric arteries (4), and carotid arteries (5) from rats. Two potential mechanisms involved in the attenuated vasodilation observed with aging are the prostaglandin and nitric oxide pathways.

Prostaglandins are a family of eicosanoids that are byproducts of arachidonic acid metabolism via the cyclooxygenase pathway. Prostacyclin ( $\left.\mathrm{PGI}_{2}\right)^{1}$ and $\mathrm{PGE}_{2}$ are the primary prostaglandins produced, and in most species, both eicosanoids are potent vasodilators. Prostaglandins have been known to play an important role in fetal development for many years. Clyman et al. (6) showed that prostaglandins (particularly $\mathrm{PGE}_{2}$ in humans [7]) were important in preventing premature closure of the ductus arteriosus in fetal lambs, and that sensitivity to $\mathrm{PGI}_{2}$ or $\mathrm{PGE}_{2}$ was dependent on gestational age. Furthermore, contractions to indomethacin were significantly greater in vessels from immature fetuses than in near term lambs (8).

Nitric oxide (NO) is produced when L-arginine is cleaved by nitric oxide synthases to L-citrulline. NO stimulates guanylate cyclase to convert GTP to cGMP and hence is a powerful vasodilator of vascular smooth muscle. As with certain prostaglandins, NO may play a role in regulation of vascular tone in vivo.

The goal of our study was to investigate any differences in vascular reactivity between infant and adult human vertebral arteries in response to agonists and to characterize our results as primarily resulting from a prostaglandin or from a NO-mediated mechanism. The hypothesis to be tested was that prostaglandins play a larger role in vascular responses to contractile agonists in infant vertebral arteries than in adult vertebral arteries, and that this difference was endothelium dependent in infants.

\section{Methods}

Human vertebral arteries were isolated within $18 \mathrm{~h}$ postmortem from infants ( $0-2$ yr) and adults ( $38-71 \mathrm{yr}$ ) who died from causes unrelated to the cardiovascular system (Table I). The vessels were immediately placed in a calcium-containing physiological salt solution $(130 \mathrm{mM}$ $\mathrm{NaCl}, 4.7 \mathrm{mM} \mathrm{KCl}, 1.18 \mathrm{mM} \mathrm{KH}_{2} \mathrm{PO}_{4}, 1.17 \mathrm{mM} \mathrm{MgSO}_{4} / 7 \mathrm{H}_{2} \mathrm{O}, 1.6$ $\mathrm{mM} \mathrm{CaCl} 2 / 2 \mathrm{H}_{2} \mathrm{O}, 14.9 \mathrm{mM} \mathrm{NaHCO}{ }_{3}, 5.5 \mathrm{mM}$ glucose, and $0.03 \mathrm{mM}$ EDTA). Under a dissecting microscope, the arteries were cleaned of periadventitial fat and connective tissues, and were cut into helical strips $\sim 2 \times 10 \mathrm{~mm}$. Where appropriate, endothelium was removed by gently rubbing the intimal surface with a cotton swab. Arterial preparations were then anchored and attached to isometric force displacement transducers (model 0.03; Grass Instrument Co., Quincy, MA), and

1. Abbreviations used in this paper: ET-1, endothelin-1; 5-HT, serotonin; L-NMMA, $N^{\mathrm{G}}$-monomethyl-L-arginine; NO, nitric oxide; $\mathrm{PGI}_{2}$, prostacyclin. 


\begin{tabular}{clclll}
\hline Gender & Age & Weight & \multicolumn{1}{c}{ Chronic therapy } \\
& $y r$ & $k g$ & & \\
Adults & & & & \\
Male & 38 & - & None & \\
Male & 62 & 77 & None & Respiratory arrest \\
Male & 60 & 64 & None & Closed-head injury \\
Male & 55 & 63 & Ranitidine & Metastatic lung cancer \\
Female & 71 & 60 & Theophylline, chlorthalidone, midazolam, KCl & Lymphoma, sepsis \\
Female & 38 & 66 & Furosemide, levothyroxine & Metastatic carcinoma \\
Female & 53 & 96 & Naproxen, acetaminophen & Respiratory failure \\
Female & 48 & - & Morphine & Metastatic carcinoma \\
Infants & & & & Metastatic breast cancer \\
Male & 2 & 12 & None & \\
Female & 0 & - & None & Myocarditis \\
Male & 0.75 & 8.6 & Digoxin, Furosemide & Respiratory failure \\
Female & 0.25 & 4 & Phenobarbital & Congenital heart disease, acute renal failure, respiratory arrest \\
Female & 0 & - & None & Perinatal asphyxia, acute renal failure \\
Female & 0.58 & 1.4 & Chlorthiazide, oxygen & Respiratory failure \\
\end{tabular}

Gender, age, weight, chronic medications, and etiology of death are listed for six infant and eight adult subjects.

suspended vertically in a $50-\mathrm{ml}$ tissue bath containing physiological salt solution maintained at $37^{\circ} \mathrm{C}$ and continuously aerated with $95 \% \mathrm{O}_{2}$ / $5 \% \mathrm{CO}_{2}$. For experiments involving endothelin-1 (ET-1), tissue chambers were coated with silicone (Sigma-Cote; Sigma Chemical Co., St. Louis, MO) to prevent peptide adherence to the glass. Tissues were then allowed to equilibrate for $90 \mathrm{~min}$ with a passive force that allowed maximal contractile activity to agonists.

Stock solutions of serotonin (5-HT) (Sigma Chemical Co.), ET-1 (Peptides International, Inc., Louisville, KY), $N^{\mathrm{G}}$-monomethyl-L-arginine (L-NMMA) (Calbiochem Corp., San Diego, CA), and acetylcholine (Sigma Chemical Co.) were prepared in distilled water with serial dilutions also carried out in distilled water. Stock solutions of indomethacin (Sigma Chemical Co.) were prepared in ethanol, with serial dilutions carried out in distilled water. Cumulative concentration-response curves were generated by addition of 5-HT $\left(10^{-11}\right.$ to $\left.10^{-5} \mathrm{M}\right)$ or ET-1 $\left(10^{-10}\right.$ to $\left.3 \times 10^{-7} \mathrm{M}\right)$ to the tissue baths containing intact and endothelium-denuded infant and adult vertebral arteries. Results were expressed as a percent of the maximal response to each agonist. To measure endothelium-dependent relaxation responses, intact adult and infant vertebral arteries were contracted with an $\mathrm{EC}_{50}$ of 5-HT $\left(3 \times 10^{-8} \mathrm{M}\right)$ followed by cumulative addition of acetylcholine $\left(10^{-10}\right.$ to $\left.10^{-5} \mathrm{M}\right)$. Results were expressed as a percent relaxation from the initial contraction to 5-HT. All experiments were repeated in the presence of indomethacin $\left(3 \times 10^{-6} \mathrm{M}\right)$ or L-NMMA $\left(3 \times 10^{-4} \mathrm{M}\right)$ to inhibit cyclooxygenase or nitric oxide synthase, respectively. Data were reported as mean \pm SEM for all experiments. $\mathrm{EC}_{50}$ values were calculated by $\log$ - $\log$ transformation and curve fitting using unweighted least squares linear regression. Unpaired Student's $t$ tests were used for comparisons of force at various agonist concentrations using a Bonferroni correction for multiple comparisons. $P<0.05$ was considered statistically significant.

\section{Results}

Both infant and adult vertebral arteries demonstrated similar concentration-dependent contractions to 5-HT over the range tested with no significant difference in responsiveness to the agonist $\left(\mathrm{EC}_{50} \sim 10^{-8} \mathrm{M}, P<0.05\right.$ ) (Fig. 1). Force generated in response to $10 \mu \mathrm{M} 5-\mathrm{HT}$ was significantly greater in adult
$(1,048 \pm 197 \mathrm{mg})$ than infant $(628 \pm 47 \mathrm{mg})$ vertebral arteries (Fig. 1, inset). Similarly, force generated in response to $0.3 \mu \mathrm{M}$ ET-1 was significantly greater in adult $(1,680 \pm 136 \mathrm{mg})$ than infant $(1,188 \pm 324 \mathrm{mg}$ ) vertebral arteries (Fig. 2, inset). However, infant vessels demonstrated an increased responsiveness to $\mathrm{ET}-1\left(\mathrm{EC}_{50}=3.3 \pm 1.2 \mathrm{nM}\right)$ as noted by the leftward shift in the mean concentration-response curve compared to adult vertebral arteries $\left(\mathrm{EC}_{50}=9.5 \pm 2.6 \mathrm{nM}, P<0.05\right.$; Fig. 2$)$. Fig. 3 shows the individual concentration-response curves to the cumulative addition of acetylcholine after contraction induced by an $\mathrm{EC}_{50}$ of 5-HT for five adult and two infant experiments. The inset shows the corresponding mean concentration-response curves and demonstrates significantly increased relax-

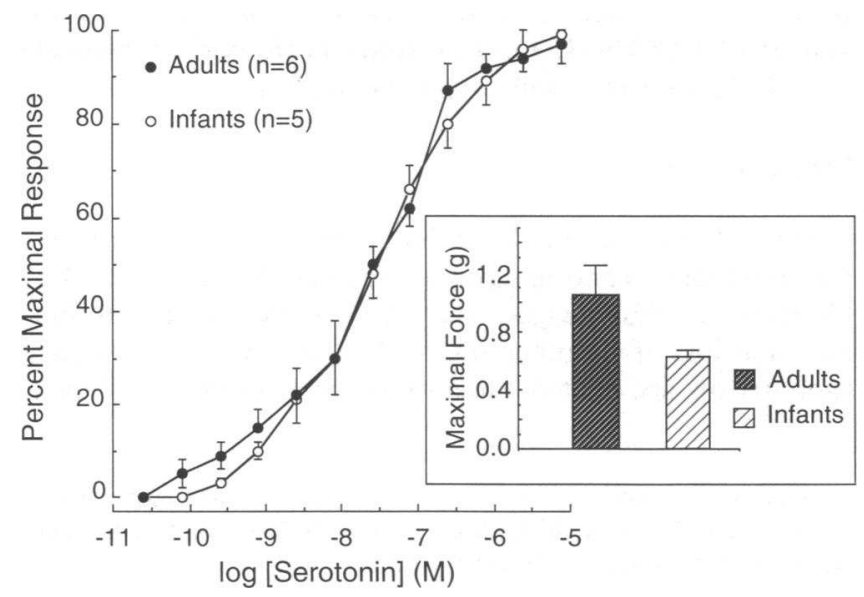

Figure 1. Contractions to serotonin. Maximal contractions to 5-HT (inset) were significantly greater in adult vertebral arteries (dark hatched bars) than infant vertebral arteries (light hatched bars), $P$ $<0.05$. However, responsiveness to 5 -HT was not significantly different between adults (open circles) and infants (closed circles). Values are the mean \pm SEM for $n$ patients. 


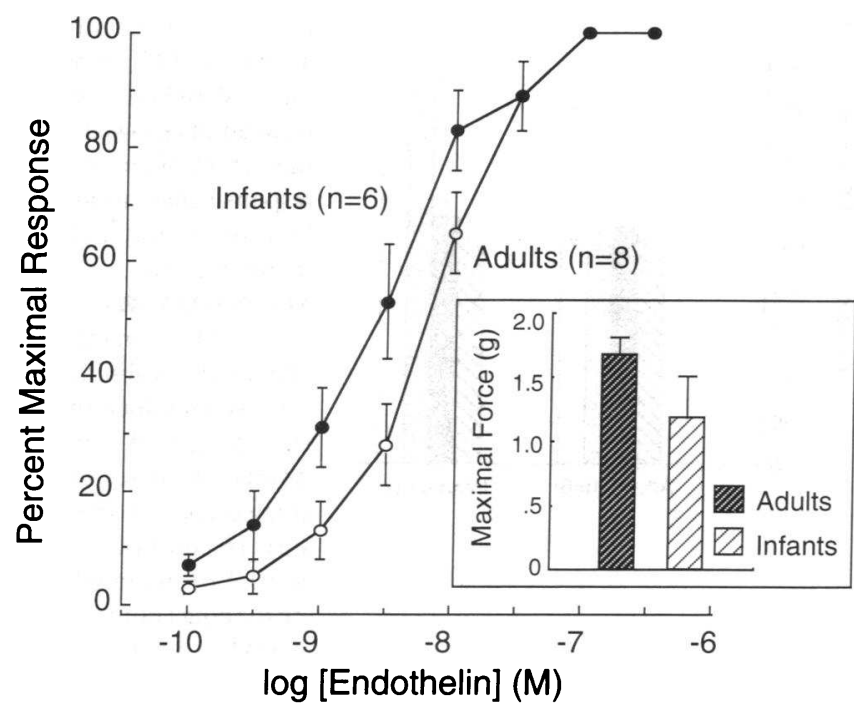

Figure 2. Contractions to ET-1. Maximal contractions to ET-1 (inset) were significantly greater in adult vertebral arteries (dark hatched bars) than infant vertebral arteries (light hatched bars), $P<0.05$. Compared to adult vertebral arteries (open circles, $\mathrm{EC}_{50}=9.5 \pm 2.6$ $\mathrm{nM}$ ), responsiveness to ET-1 was increased in infant vertebral arteries (closed circles, $\mathrm{EC}_{50}=3.3 \pm 1.2 \mathrm{nM}$ ), as evidenced by the leftward shift in the concentration-response curve $(P<0.05)$. Values are the mean \pm SEM for $n$ patients.

ations to acetylcholine in infant vertebral arteries $\left(\mathrm{IC}_{50}\right.$ $=8.6 \pm 0.4 \mathrm{nM})$ compared to adult vessels $\left(\mathrm{IC}_{50}=121 \pm 71 \mathrm{nM}\right)$ as seen by the leftward shift in the concentration-response curve $(P<0.05)$.

Contractions in infant vertebral arteries with intact endothelium demonstrated an inability to sustain contractile responses to 5-HT or ET-1 (Fig. 4), with a rapid initial contraction and a fall to a steady state $(27 \pm 13$ and $44 \pm 8 \%$, respectively) within $10 \mathrm{~min}$. Removal of endothelium or pretreatment with indomethacin potentiated the initial contraction and abolished the attenuated responses (Fig. 4). Fig. $5 \mathrm{~A}$ shows the contractions to an $\mathrm{EC}_{50}$ of 5-HT for adult and infant vertebral arteries in the presence of indomethacin, L-NMMA, or after rubbing to remove endothelium. Data are presented as percent of initial control response for each age group. The data show that none of the treatments affected the contractions to 5-HT in adult vertebral arteries; however, addition of indomethacin or endothelial denudation significantly enhanced the contractions to 5-HT in infant vessels compared to untreated, intact control vessels. Similarly, Fig. $5 B$ shows the contractions to an $\mathrm{EC}_{50}$ of ET-1 for adult and infant vertebral arteries in the presence of indomethacin, L-NMMA, or after rubbing. Again, only the infant vertebral arteries were affected by any treatment, and addition of indomethacin or removal of endothelium significantly enhanced responsiveness to ET-1. Fig. 6 shows the relaxations to an $\mathrm{IC}_{50}$ of acetylcholine in adult and infant vertebral arteries in the presence of L-NMMA or indomethacin. The data show that L-NMMA (but not indomethacin) significantly reduced the responses to acetylcholine in adult vertebral arteries ( $-16 \pm 6$ and $-96 \pm 4 \%$, respectively). In contrast, indomethacin (but not L-NMMA) significantly reduced the relaxations to acetylcholine in infant vertebral arteries $(-42 \pm 5$ and $-97 \pm 2 \%$, respectively).

\section{Discussion}

Our experimental results showed that responses of adult cerebral arteries to 5-HT or ET-1 were sustained and unaffected by pretreatment with indomethacin, L-NMMA, or removal of endothelium. In contrast, contractions of infant cerebral arteries to 5-HT or ET-1 were attenuated within 10 min after addition of agonist. Pretreatment with indomethacin or removal of endothelium abolished this decreased response, whereas LNMMA had no effect. In addition, endothelium-dependent relaxation to acetylcholine was greater in infant than adult cerebral arteries, and was abolished by pretreatment with indomethacin (but not L-NMMA) in infants and L-NMMA (but not indomethacin) in adults. These data show that endothelium-dependent contractions in infant cerebral arteries are attenuated because of an increased prostaglandin activity not observed in adult tissues.

In 1985, Hayashi et al. (9) demonstrated an increased endothelium-dependent relaxation response to $\mathrm{PGE}_{1}, \mathrm{PGE}_{2}$, and $\mathrm{PGF}_{2 \alpha}$ in premature and newborn baboon cerebral arteries compared to adults, and additional studies have shown in-

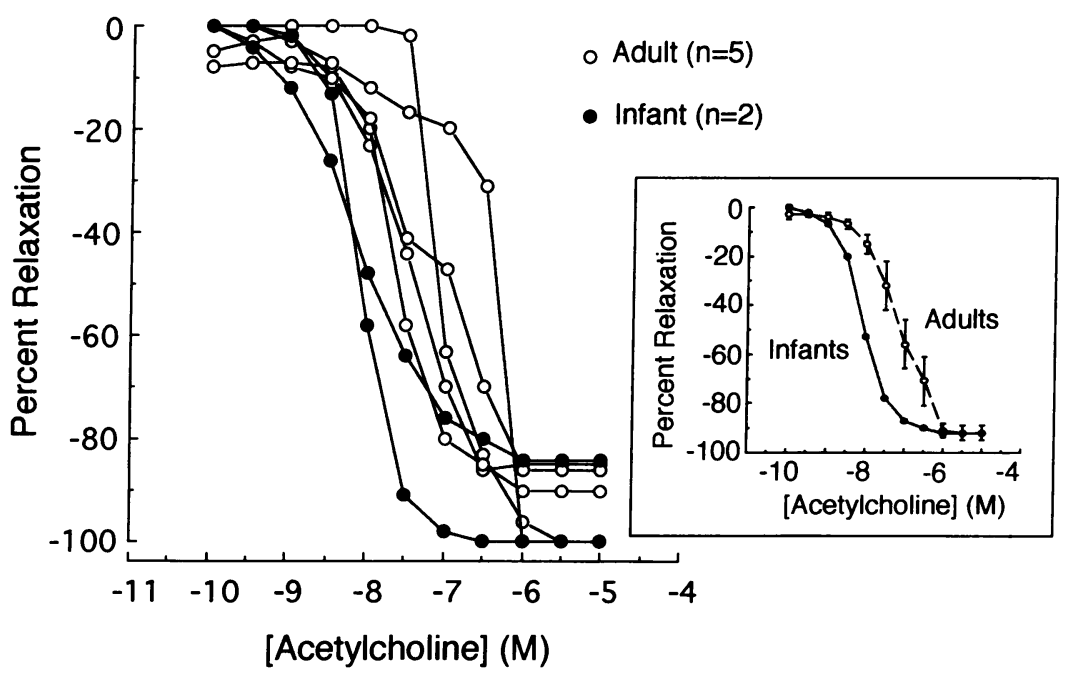

Figure 3. Relaxations to acetylcholine. After contraction to 5 - $\mathrm{HT}\left(\mathrm{EC}_{50}=3 \times 10^{-8} \mathrm{M}\right)$, infant vertebral arteries (closed circles; $\mathrm{IC}_{50}=8.6 \pm 0.4 \mathrm{nM}$ ) relaxed to a greater extent in response to acetylcholine than adult vertebral arteries (open circles; $\mathrm{IC}_{50}=121 \pm 71$ $\mathrm{nM}$ ) as evidenced by the leftward shift in the mean concentration-response curve (inset, $P<0.05$ ). Each curve represents data from a single infant (closed circles) or adult (open circles) experiment. 

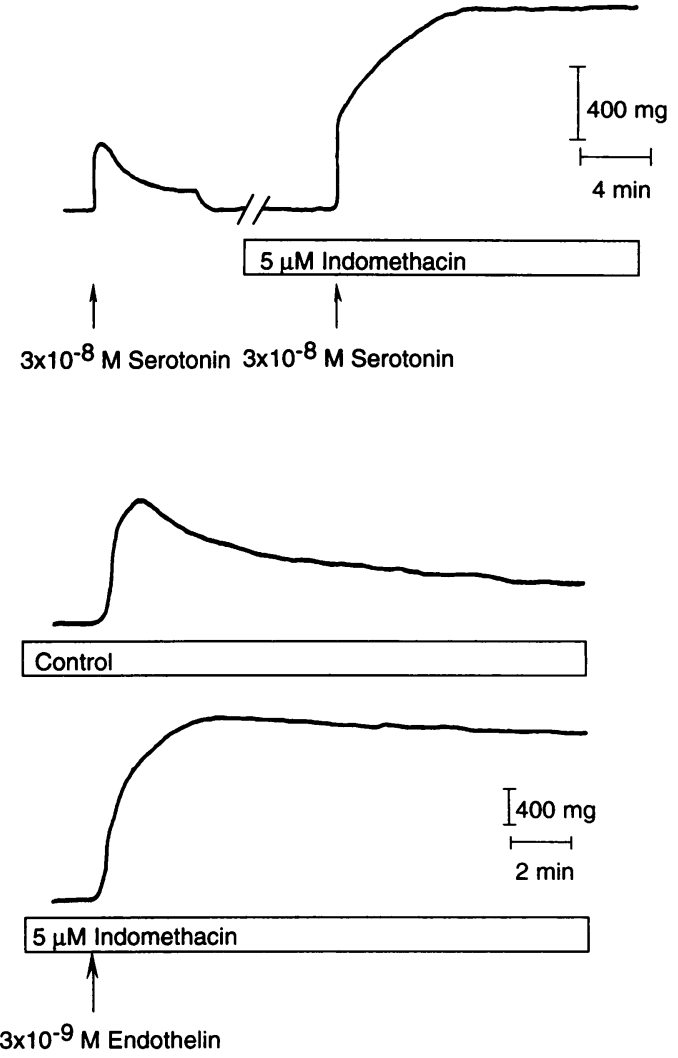

Figure 4. Contractions to serotonin and endothelin-1 in infant vertebral arteries. After addition of an $\mathrm{EC}_{50}$ of 5-HT (upper tracing) or ET-1 (lower tracing) to an infant vertebral artery, there is a rapid initial contractile response followed by relaxation within $2 \mathrm{~min}$ to a lower steady state level of contraction. Pretreatment with $5 \mu \mathrm{M}$ indomethacin potentiates the initial contractile response to 5-HT or ET-1 and abolishes the relaxation phase.

creased levels of prostaglandins in newborn humans, primates, cats, and rats, further supporting an important role for prostaglandins in infancy (9-13). Other investigators $(4,5,10,14)$ have shown an age-related decrease in endothelium-dependent relaxations. In particular, Mayhan et al. (15) demonstrated impaired endothelium-dependent relaxations to acetylcholine and bradykinin (but not nitroglycerin) in cerebral arterioles from aged (22-24 mo) compared to adult (6-8 mo) Wistar rats that were unaffected by intravenous indomethacin treatment. These findings are consistent with the hypothesis that sensitivity to prostaglandins is decreased with age and that NO is a primary mediator of endothelium-dependent relaxation in adulthood.

Results of the present study showed that human infant vertebral arteries with an intact endothelium did not sustain contractile responses to ET-1 and 5-HT. Rather, the contractions showed rapid attenuation that was abolished by pretreatment with the cyclooxygenase inhibitor indomethacin, but not by L-NMMA (an inhibitor of nitric oxide synthases). In contrast, vertebral vessels from adults responded in a potent and sustained fashion to both contractile agonists. These data suggest that endothelium-dependent contractions in human infant vertebral arteries are attenuated because of an increased prostaglandin activity not observed in adult tissues. Furthermore, we

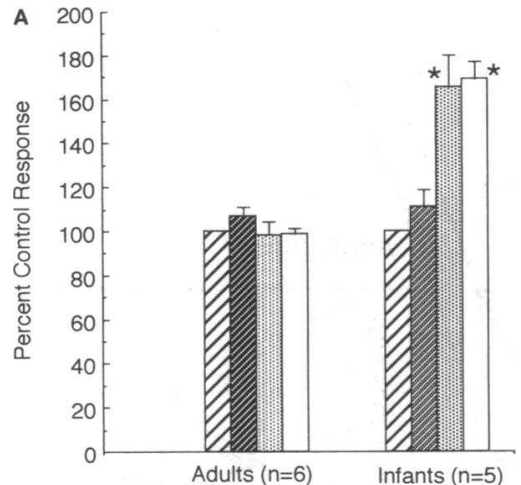

Figure 5. ( $A$ ) Contractions to an $\mathrm{EC}_{50}$ of serotonin. Vertebral arteries from adults showed no significant difference in responsiveness to an $\mathrm{EC}_{50}$ of serotonin after treatment with $3 \times 10^{-4}$ M L-NMMA (ש), 5 $\times 10^{-6} \mathrm{M}$ indomethacin (圆), or after rubbing to remove endothelium (), compared with endothelium-intact, untreated control arteries (छ). In contrast, 5 $\times 10^{-6} \mathrm{M}$ indomethacin or rubbing (but not LNMMA) significantly

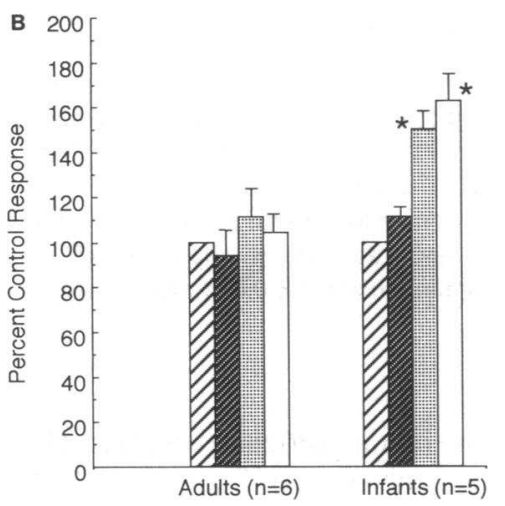
enhanced contractile responsiveness to an $\mathrm{EC}_{50}$ of serotonin in infant vertebral arteries compared to controls. Values are mean \pm SEM for $n$ patients, and asterisks represent values where $P<0.05$ compared with control values. $(B)$ Contractions to an $\mathrm{EC}_{50}$ of endothelin-1. Vertebral arteries from adults showed no significant difference in responsiveness to an $\mathrm{EC}_{50}$ of endothelin-1 after treatment with 3 $\times 10^{-4} \mathrm{M}$ L-NMMA ( $(\mathbb{)}), 5 \times 10^{-6} \mathrm{M}$ indomethacin ( $)$, or after rubbing to remove endothelium ( $\square$ ), compared with endotheliumintact, untreated control arteries $(\square)$. In contrast, $5 \times 10^{-6} \mathrm{M}$ indomethacin or rubbing (but not L-NMMA) significantly enhanced contractile responsiveness to an $\mathrm{EC}_{50}$ of endothelin-1 in infant vertebral arteries compared to controls. Values are mean \pm SEM for $n$ patients and asterisks represent values where $P<0.05$ compared to control values.

have observed that there is an age-dependent change in the primary mechanism responsible for acetylcholine-induced vasorelaxation from infancy to adulthood. In infants, acetylcholine-induced vasorelaxation was significantly inhibited by pretreatment with indomethacin, but L-NMMA had no effect. In contrast, in adult vertebral arteries, the reverse was true, and L-NMMA pretreatment resulted in significant attenuation of acetylcholine-induced relaxation, but indomethacin had no effect. Thus, in infants, the primary mechanism for endothelium-dependent relaxation is prostaglandins and for adults, NO is the major contributor. It is also possible that both enzymes are present in the infant and adult arteries, but that the smooth muscle cells show a differential response.

One speculative implication of these data is that increased prostaglandin activity or sensitivity of infant cerebral arteries may provide an explanation for the lack of cerebral artery vasospasm after intraventricular hemorrhage, a frequent complication of prematurity. In 1987, Rennie and colleagues (16) observed an increase in $\mathrm{PGF}_{1 \alpha}$ activity by radioimmunoassay in serum from preterm infants after intraventricular hemorrhage. 


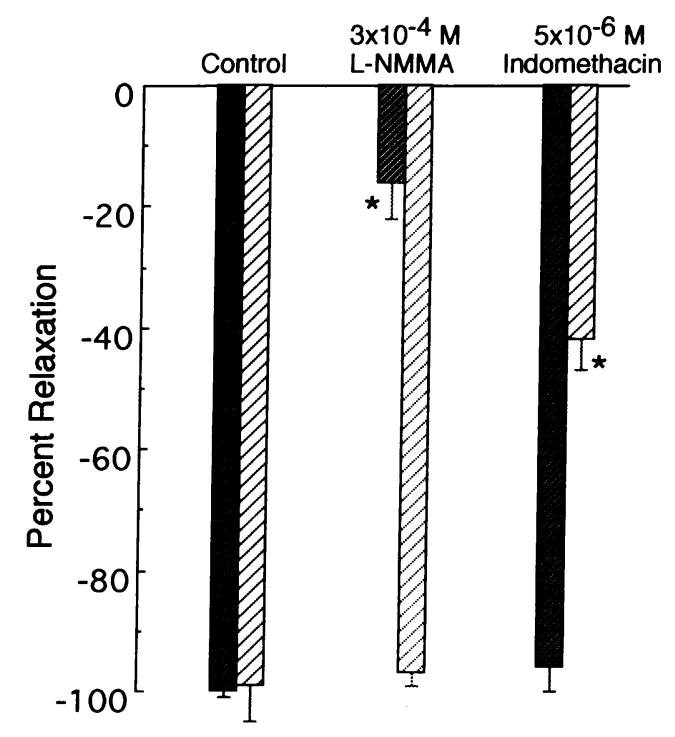

Figure 6. Relaxations to an $\mathrm{IC}_{50}$ of acetylcholine after contraction to an $\mathrm{EC}_{50}$ of serotonin. Relaxations to an $\mathrm{IC}_{50}$ of acetylcholine in adult vertebral arteries $(\boldsymbol{\Xi})$ were significantly attenuated after pretreatment with $3 \times 10^{-4} \mathrm{M}$ L-NMMA compared to controls, but were unaffected by pretreatment with $5 \times 10^{-6} \mathrm{M}$ indomethacin. In contrast, in infant vertebral arteries $(\mathbb{B})$, relaxations to an $\mathrm{IC}_{50}$ of acetylcholine were significantly attenuated after pretreatment with $5 \times 10^{-6} \mathrm{M}$ indomethacin, but not after L-NMMA treatment. Values are mean \pm SEM for $n$ patients, and asterisks represent values where $P<0.05$ compared to controls.

In fact, $\mathrm{PGI}_{2}$ has been shown to reverse contractions of human tissues to bloody cerebrospinal fluid after subarachnoid hemorrhage (12). In adults with aneurysmal subarachnoid hemorrhage, however, cerebral artery vasospasm remains the leading cause of death and disability (17).

\section{Acknowledgments}

This work was supported by grants from the National Institutes of Health (HL-18575) and the American Heart Association of Michigan.

\section{References}

1. Bar, T. 1978. Morphometric evaluation of capillaries in different laminae of rat cerebral cortex by automatic image analysis: changes during development and aging. Adv. Neurol. 20:1-9.

2. Stewart, P. A., M. Magliocco, K. Hayakawa, C. L. Farrell, R. F. Del Maestro, J. Girvin, J. C. E. Kaufmann, H. V. Vinters, and J. Gilbert. 1987. A quantitative analysis of blood-brain barrier ultrastructure in the aging human. Microvasc. Res. 33:270-282.

3. Soltis, E. E. 1988. Effect of age on blood pressure and membrane-dependent vascular responses in the rat. Circ. Res. 62:889-897.

4. Moritoki, H., E. Hosoki, and Y. Ishida. 1986. Age-related decrease in endothelium-dependent dilator response to histamine in rat mesenteric artery. Eur. $J$. Pharmacol. 126:61-67.

5. Hongo, K., T. Nakagomi, N. F. Kassell, T. Sasaki, M. Lehman, D. G. Vollmer, T. Tsukahara, H. Ogawa, and J. Torner. 1988. Effects of aging and hypertension on endothelium dependent vascular relaxation in rat carotid artery. Stroke. 19:892-897.

6. Clyman, R. I. 1978. Developmental responses to oxygen, arachidonic acid, and indomethacin in the fetal lamb ductus arteriosus in vitro. Prostaglandins and Medicine. 1:167-174.

7. Moise, K. J., G. Mari, B. Kirshon, J. C. Huhta, S. W. Walsh, and L. Cano. 1990. The effect of indomethacin on the pulsatility index of the umbilical artery in human fetuses. Am. J. Obstet. Gynecol. 162:199-202.

8. Clyman, R. I., F. Mauray, A. M. Rudolph, and M. A. Heymann. 1980. Age dependent sensitivity of the lamb ductus arteriosus to indomethacin and prostaglandins. J. Pediatr. 96:94-98.

9. Hayashi, S., K. P. Myung, and T. J. Kuehl. 1985. Relaxant and contractile responses to prostaglandins in premature, newborn and adult baboon cerebral arteries. J. Pharm. Exp. Ther. 223:628-635.

10. Hynes, M. R., and S. Duckles. 1987. Effects of increasing age on the endothelium-mediated relaxation of rat blood vessels in vitro. J. Pharm. Exp. Ther. 241:387-392.

11. Uski, T., K-E. Anderson, L. Brandt, L. Edvinsson, and B. Ljunggren. 1983. Responses of isolated feline and human cerebral arteries to prostacyclin and some of its metabolites. J. Cereb. Blood Flow Metab. 3:238-245.

12. Brandt, L., B. Ljunggren, K-E. Anderson, B. Hindfelt, and T. Uski. 1981. Effects of indomethacin and prostacyclin on isolated human pial arteries contracted by CSF from patients with aneurysmal SAH. J. Neurosurg. 55:877-883.

13. Hyashi, S., K. Myung, and T. J. Kuehl. 1986. Effects of prostaglandins and arachidonic acid on baboon cerebral and mesenteric arteries. Prostaglandins. 32:587-596.

14. Shirasaki, Y., C. Su, T. J-F. Lee, P. Kolm, W. H. Cline, Jr., and G. A. Nickols. 1986. Endothelial modulation of vascular relaxation to nitrovasodilators in aging and hypertension. J. Pharm. Exp. Ther. 239:861-866.

15. Mayhan, W. G., F. M. Faraci, G. L. Baumbach, and D. D. Heistad. 1990. Effects of aging on responses of cerebral arterioles. Am. J. Physiol. 258 (Heart Circ. Physiol. 27):H1138-H1143.

16. Rennie, J. M., J. Doyle, and R. W. Cooke. 1987. Elevated levels of immunoreactive prostacyclin metabolite in babies who develop intraventricular hemorrhage. Acta Paediatr. Scand. 76:19-23.

17. Kassell, N. F., T. Sasaki, A. R. T. Colohan, and G. Nazar. Cerebral vasospasm following aneurysmal subarachnoid hemorrhage. 1985. Stroke. 16:562572. 